\title{
O discurso da ironia e o consumo do grotesco na publicidade*
}

João Anzanello Carrascoza

Doutor e mestre em Ciências da Comunicação pela Escola de Comunicação e Artes da USP. Professor da ECA-USP e do Programa de Mestrado em Comunicação e Práticas de Consumo da Escola Superior de Propaganda e Marketing - ESPM.

E-mail: jcarrascoza@espm.br

Resumo: Os publicitários se valem de diversos recursos retóricos para divulgar produtos e serviços, assim como causas sociais e plataformas políticas. Quando produzem material para divulgar no campo os seus trabalhos, ou seja, quando o target são os seus próprios pares, a ironia se destaca, por vezes na forma do grotesco, como figura retórica central. Fato que denota não só uma escolha, mas revela ser parte do habitus profissional (Bourdieu). Neste artigo, discutiremos a retórica que sustenta a publicidade feita unicamente para o consumo dos publicitários, analisando a cena enunciativa (Maingueneau) de duas campanhas veiculadas em épocas distintas: uma, de 2005, do Clube de Criação de São Paulo e, outra, de 2010, da produtora de comerciais Corporação Fantástica.

Palavras-chave: Publicidade, retórica, ironia, grotesco, habitus.
Abstract: Advertising experts make use of several rhetoric resources in disseminating products and services, as well as social causes and political campaigns. However, when they produce material designed to highlight their own work within their own industry - in other words, when the audience is their own peers - irony stands out, at times grotesquely, as a central figure. This illustrates not only a choice, but the fact that irony is now part of their professional habitus (Bourdieu). In this article, we discuss the style that lies behind the marketing specifically designed to reach advertising people by analyzing the scene (Maingueneau) displayed in promotional campaigns from different time periods: the 2005 awards from Clube de Criação de São Paulo and the 2010 presentation by promotional producer, Corporação Fantástica.

Keywords: Publicity, rhetoric, irony, grotesque, habitus.

Desde os primeiros estudos de Roland Barthes, nos anos 1960, sobre a linguagem publicitária, vêm se intensificando, nas últimas décadas, as pesquisas sobre a retórica do consumo que tem na publicidade seu principal catalisador, embora, atualmente, avance o processo de publicização - adoção de estratégias e táticas publicitárias pelas demais modalidades da comunicação de massa. Péninou e Durand, seus seguidores, deram relevantes contribuições neste sentido, aprofundando as investigações sobre o discurso publicitário, tanto no âmbito verbal (código linguístico) quanto no visual (códigos cromático, morfológico, tipográfico e fotográfico), fazendo, inclusive, um inventário das figuras retóricas

Recebido: 02.09.2010

Aprovado: 15.10 .2010

* Uma versão deste artigo foi apresentada no Congresso Intercom 2010. 
1. ECO, U. Obra aberta. São Paulo: Perspectiva, 1976.

2. PERELMAN, C.; OLBRECHTS-TYTECA, L. Tratado da argumentação: nova retórica. 5 . ed. São Paulo: Martins Fontes, 2002. p. 22. resultantes das relações intercodicais presentes em peças publicitárias de mídia impressa.

Eco, entre outros, também se dedicou, em vários momentos de sua obra, a analisar aspectos retóricos essenciais do discurso persuasivo da propaganda que, ao contrário de uma obra aberta, seria justamente o melhor representante do que ele entendia por obra fechada $a^{1}$. Outros estudos, como os de Martine Joly, se somaram a esses, com foco na análise dos procedimentos suasórios mais comuns utilizados, em ambas as instâncias (verbal e visual), pelos criativos, na elaboração de anúncios dos mais variados tipos (institucional, de serviços e produtos, varejo, oportunidade etc.).

Contudo, escassas têm sido as pesquisas que discutem a publicidade criada para convencer ou persuadir os próprios publicitários. Ou, mais precisamente, a publicidade de produtos ou serviços cujo público-alvo são, especificamente, os especialistas em fazer propaganda. Dentro desse tipo de publicidade, destacam-se os anúncios de agências, de clubes de criação, produtoras, veículos, gráficas e fornecedores dos mais diversos serviços, dos quais uma agência de propaganda depende para entregar um material de comunicação de qualidade aos seus clientes.

É, portanto, esse tipo de publicidade e seus expedientes retóricos que nos interessam discutir aqui, até porque ela não só é produzida para aconselhar os publicitários a se decidirem por essa ou aquela empresa fornecedora, mas também para que a consumam em seu cotidiano. E, convém não esquecer, tal tipo de publicidade é feita para e, como não poderia deixar de ser, por publicitários.

Estamos, pois, num território em que o target da mensagem conhece organicamente o imaginário de quem a produz. $\mathrm{E}$ desejamos verificar se, na casa do ferreiro, o espeto é de ferro - ou de pau.

Perelman e Tyteca, em seu Tratado da argumentação: a nova retórica, nos lembram que é preciso, antes de mais nada, conhecer o auditório a que uma mensagem se destina, definindo-o como "o conjunto daqueles que o orador quer influenciar" . Podemos, no caso do discurso publicitário, nomear de auditório o público-alvo e de orador, os criativos que o elaboram e o embalam em palavras e imagens, quando veiculado em mídia impressa. Os dois teóricos também afirmam, vale lembrar, que cabe ao auditório (portanto, aos destinatários da mensagem) o papel principal para determinar a qualidade da argumentação e o comportamento dos oradores (os profissionais de Criação, produtores da mensagem). Estes últimos vão escolher os elementos suasórios para a construção das peças publicitárias de acordo com o briefing ou a estratégia criativa - ou seja, conforme as informações que devem nortear a sua plataforma comunicacional, como as características do produto ou serviço anunciado, o histórico da marca, a publicidade de seus concorrentes, o contexto socioeconômico, as peculiaridades de seu target, entre outras. Em suma, a cultura do consumidor deve ser contemplada, transposta para o discurso publicitário que lhe é direcionado, visando, assim, gerar identificação.

Sobre esse trabalho consciente do orador, que busca estabelecer a comunhão com o seu auditório, Orlandi afirma se tratar de um mecanismo de 
antecipação, que condiciona todo discurso, por meio do qual o emissor da mensagem se coloca no lugar do outro, o seu interlocutor, para ouvir as suas próprias palavras: "esse mecanismo regula a argumentação, de tal forma que o sujeito dirá de um modo, ou de outro, segundo o efeito que pensa produzir em seu ouvinte"'.

Nos dois casos que pretendemos tratar aqui, há coincidência entre o orador e seu auditório. Este pertence ao mesmo grupo daquele. E ambos, como se valem dos mesmos expedientes retóricos, conhecem profundamente as suas estratégias discursivas. Um criativo que vai fazer, por exemplo, uma campanha publicitária para divulgar os serviços de uma gráfica, destinada a influenciar outros criativos, sabe que tem do outro lado, como interlocutor, num espelho, a imagem de si mesmo. O desafio, então, retomando o mecanismo de antecipação inerente ao discurso, é de outro gênero: o emissor, desta feita, não deve apenas se pôr no lugar de seu público, para ouvir o que ele está ouvindo, mas também, uma vez nesse lugar, ouvir desse público o que ele diria ao ouvir tal mensagem, de forma a prever, enfim, a sua reação.

A este aspecto, ligado ao target para o qual o material publicitário é destinado - target que detém, como apontamos, igual conhecimento das artimanhas utilizadas pelos seus criadores -, acrescentamos um outro, associado à própria estrutura do cânone do discurso publicitário. Tal cânone, em se tratando de peças de mídia impressa, foi se consolidando, ao longo dos tempos, com uma estrutura evidentemente diferenciada daquela do discurso jornalístico, em cujo ambiente é inserido, objetivando se destacar dele. Para isso, o discurso canônico da publicidade veiculada em jornais e revistas, já que interrompe a leitura das notícias, consubstanciou, com o trabalho de gerações e gerações de profissionais de Criação, um caleidoscópio retórico cujo eixo, fiel à sua finalidade persuasiva - de conquistar a adesão de outrem empregando a suavidade ou o choque -, está em ocultar, ao menos inicialmente, o seu real intuito.

Explicando melhor: um material de cunho noticioso se apoia na estrutura de pirâmide invertida, que exige, no início, a apresentação da informação principal (a manchete), seguida das demais informações, em ordem decrescente de importância, enquanto a estrutura de um anúncio parte de uma informação secundária (um ponto de vista ou uma comparação, por exemplo) para, em seguida, no desdobramento de seu circuito discursivo, apresentar o principal (o produto ou serviço). A esse respeito, em nossa obra Razão e sensibilidade no texto publicitário, mostramos que, numa peça publicitária de imprensa, o secundário, quando a mensagem segue um viés mais racional, aparece no título em forma de proposição (tese) e, quando a mensagem é construída para produzir emoção, o secundário se concretiza no texto propriamente dito, que assume, quase sempre, o formato de história (ilustração). O fato principal, a presença do produto ou serviço - razão de ser do anúncio -, só surge num segundo momento da mensagem, envolvido num contexto, ao contrário de uma notícia ${ }^{4}$.

Assim, é elemento constitutivo do cânone publicitário essa inversão na ordem e ênfase nas etapas do discurso, quando comparado ao padrão discursivo do jornalismo.
3. ORLANDI, E. P. Análise de discurso: princípios e procedimentos. 2. ed. Campinas: Pontes, 2000 p. 42.

4. CARRASCOZA, J. A Razão e sensibilidade no texto publicitário. São Paulo: Futura, 2005. 
5. FERREIRA, A. M. (Org.). Fernando Pessoa: o comércio e a publicidade. Lisboa: Cinevoz/Lusomedia, 1986. p. 148.

6. BOURDIEU, P. As regras da arte. São Paulo: Companhia das Letras, 1996.

7. GANDRA J. R. História da propaganda criativa no Brasil. São Paulo: CCSP, 1995. p. 47.

8. SAFATLE, V. Identidades flexíveis como padrão da retórica do consumo. In: CAEPM (Org.). Bravo mundo novo: novas configurações da comunicação e do consumo. São Paulo: Alameda, 2009. p. 102.
O poeta Fernando Pessoa, que atuou como redator de propaganda, num de seus textos a respeito da arte do comércio, teorizando sobre os três princípios básicos a que toda publicidade deve obedecer, assim se expressa em relação ao primeiro (o mais importante deles), em convergência com nosso ponto de vista: "o primeiro, que é o princípio essencial da publicidade, deve ser de esconder o mais possível, o intuito publicitário"

Pois bem: em relação às campanhas publicitárias feitas para convencer e/ ou persuadir um público (os criativos) que conhece profundamente o seu arcabouço retórico, como esconder o seu intuito publicitário? Diante de um target amador, como o é na maioria das campanhas, a questão já foi resolvida, uma vez que o intuito publicitário é oculto pela inserção de um fato secundário, no início do discurso, o que já não constitui condição sine qua non, se o objetivo é mover um target profissional a conhecer e se decidir por um produto ou serviço que vai ajudá-lo a viabilizar ou aprimorar as suas ideias.

Julgamos, pois, que, diante de situações desse tipo, os publicitários, por vezes, optam justamente por não esconder, mas escancarar, na forma de ironia, o intuito de sua propaganda. Aqui, a esfinge não precisa dizer decifra-me ou te devoro, mas decifro-me para que não me devores.

Trata-se, em verdade, valendo-nos dos conceitos de Bourdieu ${ }^{6}$, do uso de um valioso capital cultural, que atua como construtor do habitus do campo publicitário.

Podemos apontar a gênese da intensificação da ironia como recurso retórico da vanguarda publicitária, com o aparecimento de Bill Bernbach, um dos sócios da agência DDB de Nova York, que capitaneou a chamada revolução criativa na publicidade estadunidense a partir dos anos 1950. Idealizador das duplas de criação - o modus operandi do trabalho ainda hoje dominante nas agências de propaganda em todo o mundo -, Bernbach é visto como um guru das velhas e das novas gerações, responsável pela principal mudança criativa na publicidade nas últimas décadas: a prevalência do vetor artístico sobre o vetor científico que então imperava desde os tempos de Claude Hopkins e as suas regras descritas no livro A ciência da propaganda. Gandra afirma que anúncios de Bernbach, bem-humorados e frequentemente irônicos, "tinham um poder de comunicação incrível. Eles conversavam com o consumidor em vez de adulá-lo"7.

Safatle, apontando a dinâmica própria da publicidade de investir e desinvestir em certas estratégias persuasivas, visto que a repetição contínua delas impõe uma lógica de desgaste de determinados conteúdos retóricos, lembra-nos de que a publicidade feita por Bernbach "ridicularizava a própria publicidade e certos aspectos da cultura de consumo".

É exatamente o que veremos nas duas campanhas que selecionamos para este estudo: uma, de 2010, da produtora de filmes publicitários Corporação Fantástica e, outra, de 2005, do Clube de Criação de São Paulo (cujos associados são criativos atuantes em agências de propaganda do Estado de São Paulo, o mercado mais representativo do país em termos de negócios e criatividade). 
Em ambas, não se adula o consumidor publicitário, mas se dialoga com ele, de igual para igual, por meio da ironia.

Remetendo-nos à antecipação do discurso, apontada por Orlandi, veremos que, sabendo previamente que o destinatário da mensagem (os criativos) detém o mesmo saber, o emissor (outros criativos) prefere não ocultar, mas revelar explicitamente o intuito publicitário. E, claro, ele o faz evitando fugir da saturação, bem conhecida por esse público consumidor em relação ao artifício básico da retórica publicitária - o secundário antes do principal -, enveredando, assim, para o universo do grotesco. Grotesco aqui entendido como manifestação de formas aberrantes e escatológicas, que vem, há décadas, se espalhando na mídia, na arte e na vida contemporânea ${ }^{9}$. Iniciemos nossa análise pela campanha da Corporação Fantástica ${ }^{10}$, composta de três anúncios. Diferentemente de outras, que variam nos anúncios a sua proposição verbal e visual, mantendo, contudo, o conceito-chave, essa apresenta a mesma proposição verbal, fundada na ironia, encabeçando três imagens distintas, do mesmo universo conceitual, o que revela a intenção dos criativos de acentuar, numa espécie de variação ilustrativa, a diversidade de sua imagética grotesca.

Na primeira delas (fig. 1), temos, em sua cenografia - cena construída pelo discurso segundo Maingueneau ${ }^{11}$-, a imagem em destaque de uma borboleta pousada numa superfície negra, tendo ao seu lado o título, num diapasão coloquial e em consonância com o auditório, "Tamo aí pra melhorar o seu roteiro". Atentando mais para essa borboleta, notamos que ela, no entanto, tem asas coloridas postiças, provavelmente de papel, e as antenas que lhe completam a forma, igualmente falsas, são agulhas de enfeite. A chave conceitual do anúncio está no corpo da borboleta, que, percebemos, é uma pequena massa disforme de fezes sobre a qual se construiu, criativamente, tal inseto. Ao fundo, vemos, fora de foco, parte de um muro e algumas árvores, comprovando que essa obra está no espaço público, rua ou calçada, em referência aos excrementos de cães espalhados pelas vias públicas.

Numa síntese da história contada por essa peça publicitária, teríamos a seguinte moral, levando em conta que seu público-alvo são criadores de filmes publicitários, cujo trabalho consiste em roteirizar ideias, posteriormente filmadas por uma produtora de comerciais: ainda que o seu roteiro seja literalmente

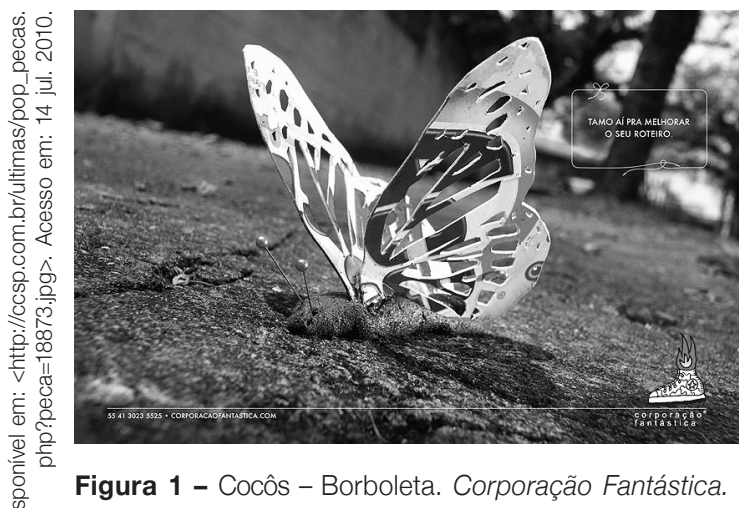
Agência: Santa Clara Nitro. Brasil. 10 nov. 2009. uma merda, nós o melhoraremos, a ponto de transmutá-lo num comercial admirável (uma borboleta).

A produtora que assina o anúncio, Corporação Fantástica, mostra, assim, por meio de uma rede semântica englobando seu texto verbal e visual, que ela tem o poder, fantástico, de transformar alquimicamente, com seu toque de Midas, o chumbo em ouro - a ideia vulgar de uma dupla de Criação em um belo filme

9. SODRÉ, M., PAIVA, R. O império do grotesco. Rio de Janeiro: Mauad, 2002.

10. SANTA Clara/Nitro, Agência. Cocôs. Anúncio publicitário, color. Brasil. 10 nov. 2009. Disponível em: <http://ccsp. com.br/ultimas/noticia. php?id $=43398>$. Acesso em: 14 jul. 2010.

11. MAINGUENEAU, D. Análise de textos de Comunicação. 2. ed. São Paulo: Cortez, 2002. 
comunicação \& educação • Ano XVI • número 1 • jan/jun 2011

publicitário. Poderíamos argumentar que, dessa maneira, a produtora estaria menosprezando os criativos, uma vez que se coloca na posição superior de agente capaz de promover o upgrade no roteiro por eles concebido. Mas, diante de tal target, como se antecipando à sua reação, os criadores do anúncio se valeram de uma provocação engendrada, ironicamente, a partir da utilização de uma imagem escatológica - não no sentido místico, mas apenas coprológico. A propósito, para Sodré,

[...] os temas coprológicos - que, na literatura de Samuel Beckett, Henry Miller ou mesmo Fernando Arrabal, são submetidos a uma transfiguração crítico-revolucionária - passam a compor, na cultura de massa brasileira, a estrutura do mau gosto e do Kitsch ${ }^{12}$.

Se, como afirma Safatle, em relação às polêmicas campanhas da Benetton, as suas rupturas formais e de conteúdos "permitiram a mercantilização publicitária da frustração com o universo publicitário"13, no caso em questão podemos dizer que há, fundeada na ironia, a mercantilização da frustração do profissional publicitário.

Os demais anúncios dessa campanha da Corporação Fantástica corroboram nosso ponto de vista e se constituem, unicamente, em variações sobre o mesmo tema, pois, como dissemos, o título é o mesmo ("Tamo aí pra melhorar o seu roteiro"), apenas as imagens ganham novos contornos do investimento no grotesco, ou, mais precisamente, outros formatos corriqueiros de fezes.

No segundo anúncio (fig. 2), temos, como cenografia, ao centro, uma árvore de Natal, com suas bolinhas vermelhas e douradas, encimada por uma estrela-ponteiro também dourada, resultante, na verdade, da inserção artificial desses elementos decorativos numa espiral de excrementos deixada sobre uma superfície negra.

O layout segue o modelo da primeira peça e, ao fundo, o edifício e veículo desfocados nos remetem às ruas de uma cidade. A história contada, agora com alguma variância em seus componentes narrativos, é a mesma: a partir dessa obra vulgar, desse dejeto - o roteiro -, a produtora faz o prodígio de metamorfoseá-lo em algo tão atrativo e mágico como uma árvore natalina, embora essa transformação, sem esconder a sua matéria-prima, deixe a nu seu resultado caricatural e cômico, característico do grotesco.

Curiosamente, a logomarca desse anunciante é um tênis do qual emerge uma labareda de fogo, o que amplia a sua rede

12. SODRÉ, M. A comunicação do grotesco: um ensaio sobre a cultura de massa no Brasil. 11. ed. Petrópolis: Vozes, 1988. p. 38.

13. SAFATLE, op. cit., p. 101.

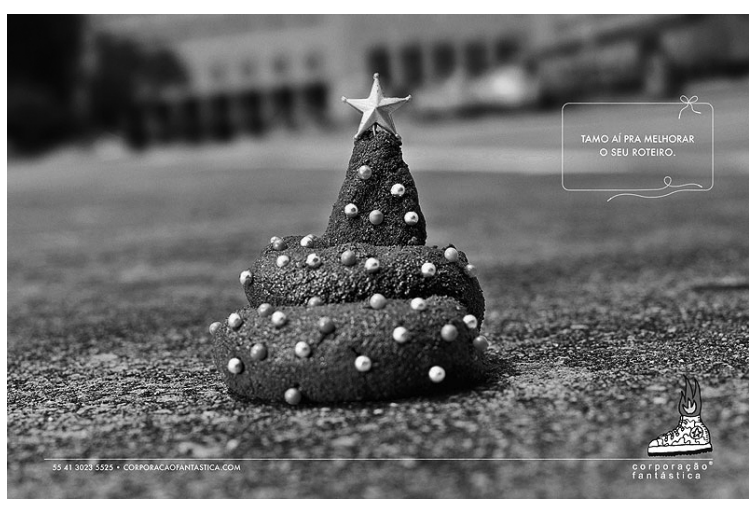

Figura 2 - Cocôs - Árvore de Natal. Corporação Fantástica. Agência: Santa Clara Nitro. Brasil. 10 nov. 2009. 


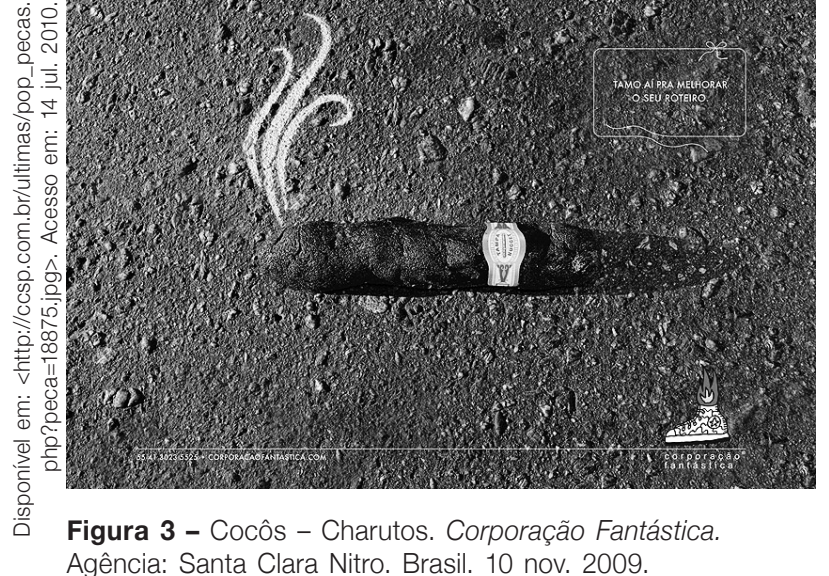

é mole e, no segundo (a árvore de Natal), pastoso.

Passemos, a seguir, a nos deter na campanha para o Clube de Criação de São Paulo ${ }^{14}$, composta de dois anúncios, que divulgam os 30 anos dessa entidade, e, à semelhança da campanha da Corporação Fantástica, é feita por publicitários para publicitários. Por se tratar de um clube, que reúne criativos, o intuito da propaganda não é vender produtos e serviços como uma produtora de comerciais, mas vender o clube como instituição legitimadora da criatividade publicitária, e, mais especificamente, o seu prêmio (que resulta num anuário), para diretores de Criação, diretores de Arte e redatores.

O primeiro anúncio criado pela Agência F/Nazca S\&S (fig. 4) traz, como cenografia, uma sala de reuniões típica de agência de propaganda, na qual estão sentados em cadeiras, representando os criativos que ali se juntam para fazer brainstorm ou discutir estratégias acerca de algum job, cinco excrementos iguais, do mesmo formato (espiralado, cônico), e uma estrela dourada (símbolo da premiação anual do CCSP) que, obviamente, se destaca pelo seu brilho, pela sua singularidade, ante os dejetos ao seu redor.

A narrativa que se delineia ali, hiperbolicamente como costuma ser quando se caricaturiza uma situação, é simples, além de expressar com transparência a luta pelo poder no campo publicitário; e a podemos sintetizar da seguinte maneira: o profissional premiado por esse clube é uma estrela, goza de prestígio e se destaca numa equipe de Criação, enquanto os que não ganham o prêmio são, ipsis litteris, uns bostas. Tal proposta criativa, levada a cabo discursivamente pela escolha do escatológico, tanto

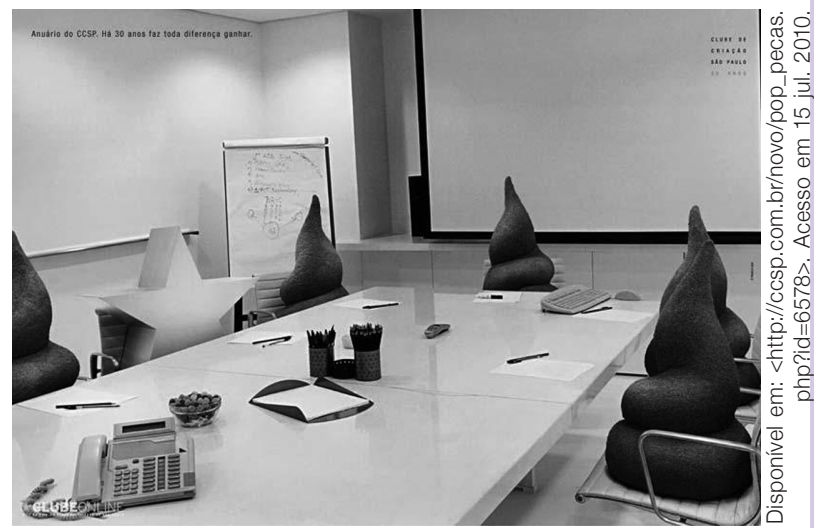

Figura 4 - Anuário do CCSP. Há 30 anos faz toda diferença ganhar - 2. Clube de Criação de São Paulo.

Agência F/Nazca S\&S.
14. F/Nazca S\&S, Agência. Há 30 anos faz toda diferença ganhar. Anuário do CCSP. Anúncio publicitário, color. 2005. Disponível em: <http:// ccsp.com.br/busca/busca. php? SearchArea = novo $\& \mathrm{t}=\mathrm{h} \% \mathrm{E} 1+30+\mathrm{anos}+\mathrm{faz}$ +toda+diferen\%E7a+g anhar>. Acesso em: 14 jul. 2010. 
quanto na campanha da Corporação Fantástica, é ratificada pelo seu título, "Anuário do CCSP. Há 30 anos faz toda diferença ganhar".

$\mathrm{O}$ anúncio reproduz, assim, com ironia, o princípio de hierarquização interna ${ }^{15}$ - legitimação exercida dentro do campo pelos pares -, ao mostrar, sem meio termo, a instância de poder mais alta e a mais baixa na hierarquia do campo publicitário, em se tratando de criatividade. Em suma: essa peça comemorativa dos 30 anos do anuário do CCSP revela um traço do habitus profissional dos criativos - os prêmios concedidos pelo Clube incrementam o seu capital simbólico, favorecendo a sua ascensão.

O segundo anúncio (fig. 5) demonstra, de modo ainda mais direto, a luta pelo poder no campo e o peso que, na ótica de seus criadores, os prêmios do CCSP têm.

O título, que carrega o posicionamento do anunciante, é o mesmo do outro anúncio da campanha: Anuário do CCSP. Há 30 anos faz toda diferença ganhar. A sua cenografia é similar, mas agora não temos uma sala de reuniões com vários profissionais, e sim

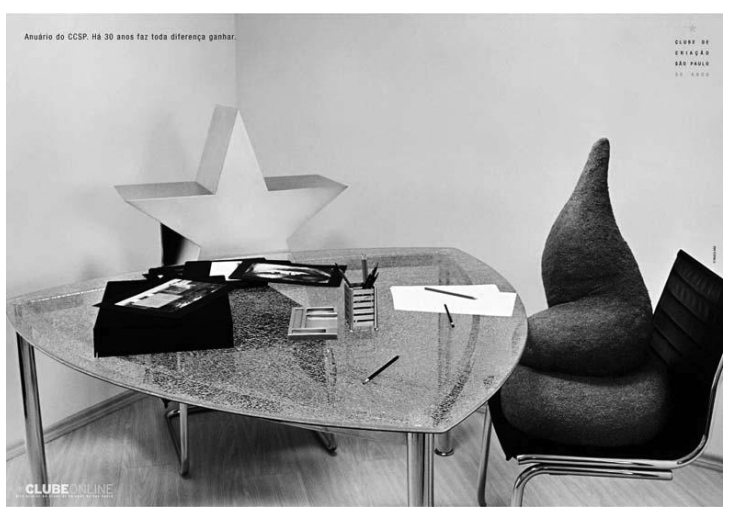

Figura 5 - Anuário do CCSP. Há 30 anos faz toda diferença ganhar - 1. Clube de Criação de São Paulo. Agência F/Nazca S\&S. uma pequena sala na qual se con-

frontam um criativo estrelado, que apresenta o seu portfólio, e um outro, que o avalia, um merda, na sua opinião - e, certamente, na de seus pares -, como a imagem bem o demonstra.

Estamos, pois, frente a frente com uma das situações mais comuns no âmbito do trabalho publicitário - o instante, entre dois profissionais de Criação, em que se averigua qual deles tem mais capital simbólico no campo. E a própria cenografia já esclarece que é o criativo premiado pelo CCSP; é ele quem, por ironia, ocupa a posição hierárquica mais acima, ao ser escolhido para aparecer na cena enunciativa como o avaliado e não como o avaliador - esse, grotescamente, representado não como alguém menos estrelado, mas como um cocô.

Dessa feita, nos dois anúncios dessa campanha (CCSP), assim como nos da anterior (Corporação Fantástica), o intuito publicitário não é oculto, mas abertamente encenado. Orador e auditório em ambos os casos partilham do mesmo ideário, do mesmo habitus profissional, das mesmas angústias criativas. Aliás, Kayser ${ }^{16}$ afirma que o grotesco irrompe onde o homem se vê inseguro diante da vida, sendo, portanto, a manifestação de uma angústia. Seria, aqui, a angústia do criador diante de um outro que conhece tão bem os seus estratagemas retóricos?

Sim, por meio desses exemplos, podemos dizer que a angústia dos cria16. KAYSER, W. O grotesco. São Paulo: Perspectiva, 1986. dores foi incorporada ao estoque de recursos persuasivos do qual eles lançam mão para fazer suas peças publicitárias e, assim, mercantilizada em forma de 
uma estratégia centrada na ironia. Ironia que é a modalidade discursiva na qual se pode flagrar uma diferença entre o que é literalmente dito e o que se quer verdadeiramente dizer. No fundo, sabemos, a Corporação Fantástica não deseja depreciar a competência daquele que a escolherá como um aliado na produção de seu roteiro. Os associados do CCSP também não acreditam que o prêmio de seu anuário é o legitimador soberano do talento dos criativos, até porque, como a premiação é anual, pode-se ser um profissional estrela num ano e bosta no outro.

Como destacamos, nesses dois casos os publicitários são emissores e destinatários da mensagem. Na condição de destinatários, se adotarmos a acepção de $\mathrm{Eco}^{17}$ sobre os tipos de leitor existentes, eles não são leitores semânticos (que, diante de uma história, querem saber o que acontece), mas semióticos (que desejam saber como aquilo que acontece é narrado). Não por acaso, a ironia é uma estratégia retórica que prevê, em seu próprio bojo, o movimento do outro - o saber do leitor semiótico. Ou, como aponta Brait, é uma forma de construção que denuncia um ponto de vista e "conta com a perspicácia do destinatário para concretizar-se como significação"18.

No fundo, os publicitários que criam peças para influenciar outros publicitários sabem que seus pares mais consomem os anúncios a eles destinados do que creem em suas mensagens. É a lógica do Papai Noel, como afirmou Baudrillard ${ }^{19}$ acerca da publicidade. Uma lógica voltada menos para o enunciado e a prova, e mais para a fábula e a adesão. Não acreditamos no produto, mas na publicidade que quer nos fazer crer nele. Para os criativos, uma irônica e, por vezes grotesca, forma de diversão.

\section{REFERÊNCIAS BIBLIOGRÁFICAS}

BAUDRILLARD, J. O sistema de objetos. São Paulo: Perspectiva, 1993.

BOURDIEU, P. As regras da arte. São Paulo: Companhia das Letras, 1996.

BRAIT, B. Ironia em perspectiva polifônica. São Paulo: Ed. Unicamp, 1996.

CARRASCOZA, J. A. Razão e sensibilidade no texto publicitário. São Paulo: Futura, 2005.

ECO, U. Obra aberta. São Paulo: Perspectiva, 1976.

Sobre literatura. Rio de Janeiro: Record, 2003.

FERREIRA, A. M. (Org.). Fernando Pessoa: o comércio e a publicidade. Lisboa: Cinevoz/Lusomedia, 1986.

GANDRA, J. R. História da propaganda criativa no Brasil. São Paulo: CCSP, 1995.

KAYSER, W. O grotesco. São Paulo: Perspectiva, 1986.

MAINGUENEAU, D. Análise de textos de Comunicação. 2. ed. São Paulo: Cortez, 2002.
17. ECO, U. Sobre literatura. Rio de Janeiro: Record, 2003.

18. BRAIT, B. Ironia em perspectiva polifônica. São Paulo: Ed. Unicamp, 1996. p. 16.

19. BAUDRILLARD, J. O sistema de objetos. São Paulo: Perspectiva, 1993. 
comunicação \& educação • Ano XVI • número 1 • jan/jun 2011

ORLANDI, E. P. Análise de discurso: princípios e procedimentos. 2. ed. Campinas: Pontes, 2000.

PERELMAN, C.; OLBRECHTS-TYTECA, L. Tratado da argumentação: a nova retórica. 5. ed. São Paulo: Martins Fontes, 2002.

SAFATLE, V. Identidades flexíveis como padrão da retórica do consumo. In: CAEPM (Org.). Bravo mundo novo: novas configurações da comunicação e do consumo. São Paulo: Alameda, 2009.

SODRÉ, M. A comunicação do grotesco: um ensaio sobre a cultura de massa no Brasil. 11. ed. Petrópolis: Vozes, 1988.

SODRÉ, M.; PAIVA, R. O império do grotesco. Rio de Janeiro: Mauad, 2002. 